\title{
CHANGE MANAGEMENT THROUGH IMPROVEMENT OF THE PRODUCTION STRUCTURE OF TRANSPORT - NEW CHALLENGES
}

\author{
Vasko Vassilev \\ “Todor Kableshkov" University of Transport, Sofia, Bulgaria
}

\author{
(C) MESTE NGO
}

JEL category: L9, R4, R41

\begin{abstract}
The problem of the study, design and the improvement of the structures is not a new theory. In this area employs a large number of scientists, there are many scientific studies and developments. However, the current dynamics in changes of new scientific results and greater needs of the economy has made it necessary to expand the scope of research. This is particularly important for transport of the effectiveness of which depends largely on the overall economy.

The actuality of the problem is especially great given the following important issues that need to be addressed:

- The construction of the structures of the transport system is directly dependent on the structure of the national economy.

- In turn, the structure of the transport directly affects territorial and product restructuring of the economy.
\end{abstract}

Keywords: transport, restructuring, production structure, cybernetic system, structural units of transport, effectiveness, structural factor, elements of the system, transport modes, common transport system

\section{INTRODUCTION}

Restructuring of the economic system is highly topical scientific and practical problem in terms of economic reforms. Criteria and factors for research and analysis of production structures

Address of the author:

Vasko Vassilev

䤵 vasko.ananiev@gmail.com and especially to the procedures for design and management of these processes are relatively less explored area. Here we present an attempt at a new approach to managing changes. The proposed approach to integrate the capabilities of cybernetics and systems approaches.

This concept was fundamentally new and allows for a comprehensive analysis of the problem structure and the design of effective production structures taking into account the complex of 
relations between different sectors of the economy in hierarchical and horizontal plan.

The proposed methodology can be successfully adapted to different economic systems.

The problem for the study and improvement of the structures and economic systems is essential for their effective functioning. The task for a new approach to the restructuring can be decided only on the basis of complex systems research. It is impossible to solve correctly the structural problems of the economy, if not used modern scientific achievements of the theory of systems and their management. On this basis it is possible the development and use of modern approaches and methods of research and analysis of the structures, and the right choice of alternatives for their development and application of appropriate technology for practical transition to the new structures.

Past experience shows that restructuring is most often limited to modifications of existing structures based primarily on intuition or partial studies. This is the reason for allowing conceptual errors with serious negative consequences.

The output of the production structure as an object of study and improvement was required for it to be considered as a separate system object and its elements. Basic position for evaluating the effectiveness of the production structure is its consideration as a cybernetic system with the corresponding input and output. Parameters input can be described as a relatively independent system with the own structure of its elements.

The need for a scientific approach to the improvement of the structure is particularly topical for the transport system.

Transport is one of the main sectors of the economy. This is determined by its particular role in the overall reproduction process, along with that it is a basic condition for the production of material goods.

For transport as a system and its place can draw conclusions based on the following important information:

- Production resources of transport are about $15 \%$ of the whole economy, and the share of investment exceeds $8 \%$.
These data indicate not only the scale of transport as a system, but also its significance for the whole economy. Violation of transport processes and relationships can have negative consequences for other sectors. The role that transport has on the effectiveness of the national economic complex and the overall social and cultural life requires it to investigate so as to cover all processes and relationships that are directly related to its functioning. On the other hand the structure of the transport complex is most closely correspond to the structures and the respective needs of freight and passengers according to their structure, spatial location, dynamics of rise and fall over time.

- Production and structural units of the transport system is characterized by a wide variety of functions, objectives and technological processes. They have separate dynamic performance and other characteristics of the processes for preparation of the final product. Along with this activity is directed to of a unified goal - to provide the transport process.

This objective can only be achieved by not less complex system of united technological and managerial procedures and integrated system for the implementation of information, technological, resource, organizational, economic and social relationships where the single technological process requires an extremely coherent system of these links requires a high degree of organization in carrying out the integration relationships.

\section{INTEGRATION OF TRANSPORT MODES IN A COMMON TRANSPORT SYSTEM}

In building integrated functionally, organizationally and technologically complementary production structures, transport should be considered as:

First: As a single cybernetic system, where the entrance is the impact of the environment and the output results of the system as a whole. It is well known classic scheme, but the problem is that too often stop its adoption and unfortunately arbitrary interpretation. Evaluation of the effectiveness of the system is usually done by comparison with other systems and their parameters of input and output. This information is incomplete and in most cases leads to conceptual errors that cost billions. 
Therefore should be assessed real environment directly connected to the research element of the system, in this case the production structure. The structure of the common transport system parameters of the production structure elements / modes / are treated as external environment.

The following procedure is the consideration of each mode as a separate cyber system with the external transport environment, the impact of other modes of transport and structural elements of the mode of transport.

This approach is repeated until a hierarchical level that is high enough weight factor influencing all the structural elements of the transport system. For example, the proposed approach container terminals are systems of fifth order in the system hierarchy of the production structure of transport. But their consideration as a separate system is necessary because they have a structure important matter for all modes.

Determining here are single transport industrial and technological relations. Without their real metering and optimization is impossible to make a real feature of the system-wide transport. Coordination of characteristics of the subsystem is mainly through optimization of these links in a three-dimensional direction - both hierarchical and horizontal directions.

Second: In contrast to industry, transport the major part of the funds constantly change position. Diversity of relationships with the external environment and the dynamics require adequate speed of reaction, while there is great uncertainty, requiring a high level of adaptability. Flexibility is creativity, greater knowledge of the general laws of the transport process, flexible information system "lightning " movement and implementation of management decisions and feedback to and from all parts of the system with two words, less flexible, adaptive, dynamic and highly efficient structures. These requirements apply to all dynamic systems, but most transport.

Third and very important feature of the system is its humanity and all the attendant requirements to employees. In transport workers and employees working in around 560 different types of jobs with different levels of qualification. These figures show that the management of human potential itself as a system is very complex task and requires special attention and detailed analysis.

\section{FUNDAMENTAL STRUCTURAL UNITS OF THE TRANSPORT SYSTEM}

Above described general system characteristics of transport are the basis for the complexity of the structure as an object of study. Full description of the structural units of transport is impossible within this development. For this reason, we will point out only the main components of the "production" structure. Structure elements of the functional structure of transport characterizing the output of the transport system in two main areas - transport of passengers and freight are:

- Rail transport

- Road transport

- River Transport.

- Sea Transport

- Air Transport

- Pipeline transportation

- Urban Transport

- cabin lift

- Other modes of transport and logistics

Comprehensive solution to the structural problems of transport requires restructuring of all the modes of transport and activities taking account of the proportions between them and the proportions between transport and other sectors. This condition is necessary in order to obtain maximum benefit from the operation of transport in general. To evaluate the effectiveness of the structures of transport need to be analyzed and a number of quality characteristics in the development of modern transport and on this basis to determine the baseline.

Modern transport development strengthens its role as an essential tool for the effective functioning of the whole economy as a major balancing factor between sectors and territories of individual countries as an important factor in solving the social, cultural, infrastructural problems and intensification. This crucial role of transport determines the main directions of its development in recent years in the following areas:

- Update technologically and structurally. Here the focus is primarily on the priority inserting 
and cutting-edge technologies and the development of economical modes of transport.

- Improving the quality of transport services. Increasing the transport speeds, specialization, the development of combined transport, reducing the stock of materials for the time only about their transportation without downtime.

\section{RESEARCH AND PRACTICAL TASKS IN RESTRUCTURING}

Problems can be solved after the development and adoption of a unified science-based concept and technology development projects and restructuring of transport. Decisive tasks now do not include any specified task that is associated with the restructuring of transport. Indication of such problems is to rely permanently on the old approach, the results of which show that can be achieved only general disclosure of the problem situation and outlining the guidelines. The main factors that influence in this direction are:

- All too often, the market as "automatic controller" as absolute as a major structural factor. This is especially dangerous for transport because on the one hand to the need for a comprehensive, scientifically and strategically well-balanced structural policy and the other - not the specific characteristics.

- The old approach has exhausted its possibilities and therefore more complicating structures of the transport system and the complexity of technological processes and relationships. This implies the depth of research and discovery of the whole complex of relations, processes and relationships underlying effective performance as a whole. Restructuring of each subsystem of transport should be considered and agreed by the iterative procedure with the other structures. Their organizational, technological, economic and functional integration is the basis for the formulation of a "framework" in which the construction of each business unit will have optimal parameters and effective functioning of the public scale.

All this cannot be solved with existing tools and scientific and practical methods. We need a fundamentally new scientific approach through which to cover systemic / or more approaching to it / on the large set of factors for optimization of structures.

The complexity of the transport system and its features as a single multi-tier system of a large area suggests a qualitatively new approach to restructuring. All experiments show that over the past 10 years the changes are made through the old routine and partly scientific methods and do not give the required result. For this purpose, the need for comprehensive research in terms of:

- demand for transport and the dynamics of their development;

- transport options to meet the needs, the necessary pace and directions of development,

- modal, which are based on the structure of industries and cargo and passengers;

- Transport as part / subsystem / from one socio - economic system.

This requires the development of systems theory and methodology for the study and design of transportation structures and application of uniform approaches, methods and criteria for analysis and evaluation of the structure of transport and existing information bases, raise fundamentally new information and choosing the correct option structuring of transport. Any other approach absolute one or other system characteristics or facilitate the rational structure would again lead to subjectivism and wrong decisions. Again, they will cause major imbalances in the structures of the different modes of transport and between them. As a result, continually persist bottlenecks to be removed piece and contradictions will intensify.

Now there is a real danger to the structures of which have a strong hierarchical structure. By continuous strong centralization can switch to unreasonably greater decentralization, leading to new imbalances and huge losses in the public scale.

To solve these tasks is necessary disclosure of the problem situation, characteristic of the transport system and on this basis to determine: Does the study and improvement of structures; what are the main problems to be solved given the current state of transport with what methods and how to organize the study. Attempt to solve these 
problems is made in this paper. Its further expansion, however, is beyond the power of a researcher and a complex examination must have the following conditions:

- Availability of theoretical and methodological tools for analysis, design and structural improvements.

- Willingness to conduct and financing of major research and design.

- Built research and design engineering team. It is a clear concept for the purpose, structure, operation and management of the team itself.

\section{METHODOLOGICAL PROBLEMS IN THE RESTRUCTURING OF THE TRANSPORT SYSTEM}

Extracted features of transport in large, complex and dynamic system make it necessary to carry out a thorough analysis of structurally complex factors. The test must be obeyed model in which to solve the following tasks:

- Achieving maximum scope of elements that are crucial for the establishment and operation of production structures.

- Develop a methodology providing complexity and unity in the approach to the restructuring of the elements in the entire hierarchical and horizontal chain transport system.

- Combining "The theoretical" content and "inclusiveness" of the study to be invariant for all subsystems.

- Definition of objectively necessary for the transport characteristics of meaningful research methodology and content of the stages of research, design and improvement of production structures.

- The nature, content, thematic scope of the study, analysis and design of production structures and highlights the evaluation of conceptual designs and deciding on the application of the chosen structural model.

In essence, the task is to develop the basic problems of the content of the research methodology. It should be emphasized that the possible logical structure of the content of the research project and task cannot be fully comprehensive. This is natural given the complexity of the object to which it develops. At the same time the aim is to offer a construct that defines the methodological framework which can complement the new elements in research and design in accordance with the specifics of the objects and purposes of the study. The main thread, the proposed research approach is a system -oriented research and design and implementation of complex results.

The parameters of the elements of the structure of production are described as the input of the transport system, and the assessment of their effective use to be made after the comparison with the results at the output. Their evaluation is qualitative and quantitative, and covers the most common material, financial, informational and social impact resulting from the operation of transport. On this basis, determines the efficiency of the operation as a separate set of selected indicators of inputs and overall system efficiency. The study is done generally on several levels. At the first level is made describing / inventory / transportation structures as a whole. An assessment of the conformity of production structures and their functional characteristics of the structures of the external environment in the context of the ability to satisfy its needs.

Second hierarchical level / or right next order procedure / transport is seen as a cybernetic system with appropriate input-output parameters.

Thus established: effectiveness of physical, financial, informational, scientific and technological exchange between transport and the environment; reveal to white flight, unused mutual opportunities density of connections and the main problems to be solved in this direction; open possible alternative solutions to meet the needs of the external environment and the necessary structural changes in transport; doing is an overall assessment of the effectiveness of the functioning of the transport system selected quantitative and qualitative criteria.

At the next level the same procedure is repeated for modal their structural subdivisions, etc. up to the level which is necessary to decide exhaustive research task. The depth of study is determined by the weight factors which have certain hierarchical levels on solving the problem. Indicate discontinuation of the study was the sharp drop in the magnitude of the impact of the next level regardless of the direction of research in space. This is a principle that we conventionally call „fading effect of the impact." 


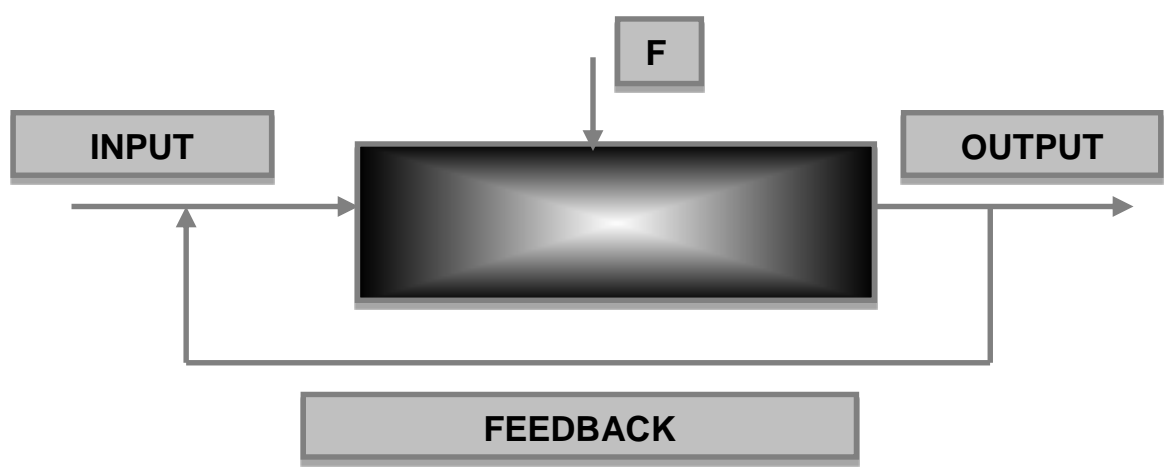

Fig. 1 Elements of the system (cybernetic approach) ${ }^{1}$

For example, for the study and design of the structure of the transport system have certain criteria important to the regional European level / structures in the external environment in the country and the Balkans / and other / example for technological connections to / from the global level. In decreasing term, the most important are the structures of the first rank divisions of different transport modes.

Horizontally, the factors which have a relatively high density of connections, and thus a high degree of impact.

We should emphasize that in the literature this topic is poorly researched and lacking a formal mathematical or logical model for determining the boundary of fading away / minor / impact. This problem is under study and is hardly forces the author to solve it alone within the limited time available for testing. To overcome this systemwide theoretical and methodological difficulty here will offer the hypothesis that the degree of impact is high up to a certain threshold, after which its value falls sharply and the amount of the magnitude of the impact of all other / essentially endless array of levels / always less than the sum of the effects of rows before plunging .

The application of this hypothesis possible reference ranges only when a reexamination of relatively stable systems and when the first / comprehensive study / are described, and the degree of their influence on the parameters of the object. For this reason we will assume that the boundary of the study will be determined by the density of connections and their importance for the subject and the significance factor.

The second research line is parallel to the first and carried out in compliance with the principles outlined above. Object of study are structural elements of general systems research object. In the first approach in depth study was carried out on the "identification of the elements of the black box by subject statuses, i.e. when objects / black boxes of the next level are actually existing, identified and defined as subsystems as their study on cyber.

The second beam research is carried out conditional call it "systematically opening and identification of the black box 'of the functional status of the items. This is a research task of almost all scientists in system theory, which has not yet decided on a unified theoretical and methodological basis. Nevertheless, the proposed approach for the identification of functional elements of the transport system is an attempt to put into practice the achievements of scientists in this field and to contribute to the practical solution - improvement of the structure of the transport system.

The proposed parallel study on cyber and systemfunctional approach is an attempt to direct the research in accordance with the hypothetical herein defined "double helix social system objects." Agreed results of these comparative studies can provide valuable results service

\footnotetext{
1 System, viewed as relatively independent site management is presented as a black box, which implements processes for the conversion of input to $(X)$ resources to achieve certain results to the output $(Y)$. This process is carried out under constant external influences $(F)$.
} 
design options structures of production and selection of the optimal model.

Proposed elements as an object of study are not sufficiently comprehensive systemic perspective. Their selection is made in accordance with the specifics of the site and serving as the maximum proposed approach. More important are the formulation, classification and analysis of:
- Objectives

- Functions

- Technologies and mechanisms

- Structures

- Resources including material, labor, financial, information and innovation.

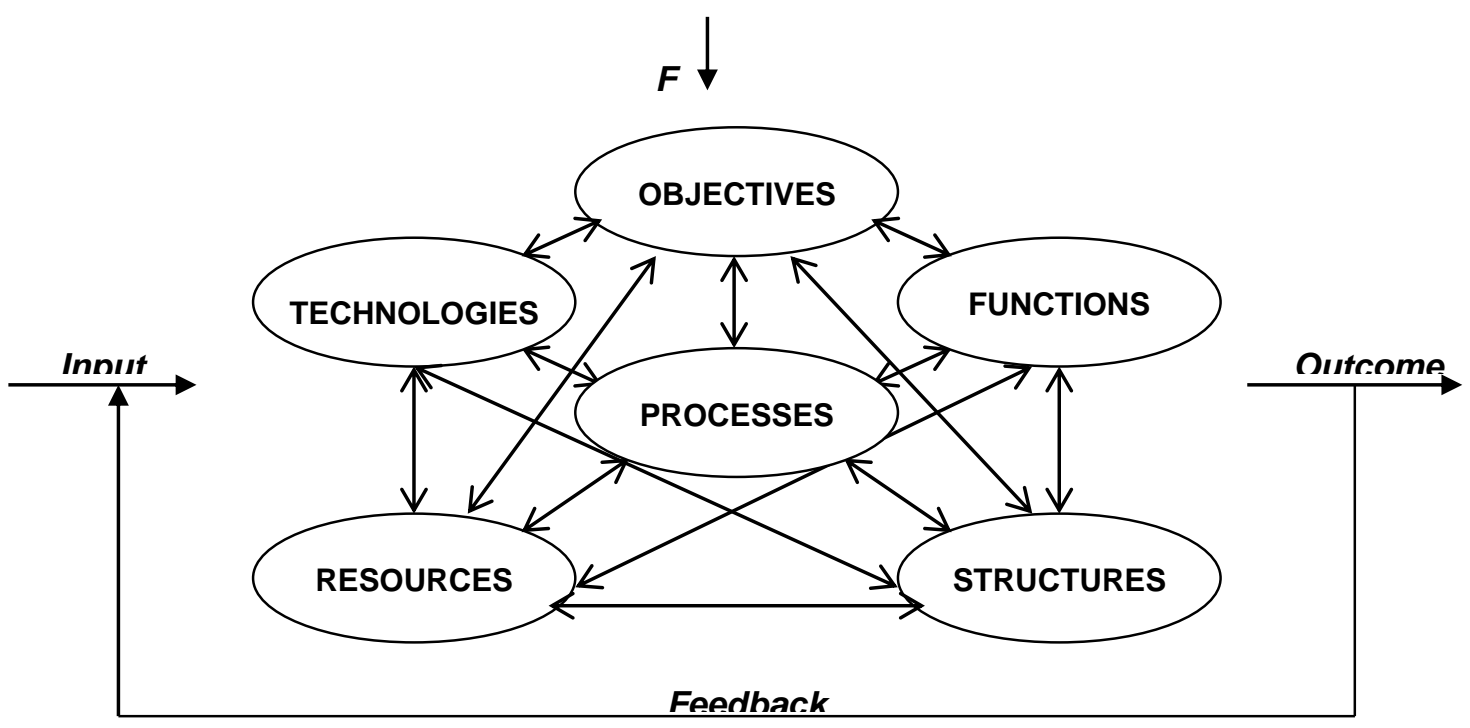

Fig. 2 Principle model of integration elements

\section{CONCLUSIONS}

Summary of the contents of this study lies in the following:

- Each functional element is considered as a single system and its "ideal" parameters and specifications comply with all the others, where the structure has equal importance.

- The results of this study are used in conditional output of the structure as a system of I rank. In this procedure, determine the necessary limits of structural change and the new parameters of the other elements, but only eligible / in systemic context / framework. These results are used directly in the design of I version of the model and then iteratively re-ordination is developed II version, etc. to afford an optimal balance of the structure model.

The resulting models from this study agree with the models of the research cybernetic approach / one of two parallel research directions / and proceed to the final stage, the actual design.
The proposed methodology is based on cybernetic and systemic approaches. This creates conditions content and the procedural steps to be used in the restructuring of other industries and manufacturing sectors. The studies suggests a contemporary approach which outlined the most important (providing an exhaustive detection of problem situation) procedures for analysis and design. In their practical realization of teams can without problems to fit different approaches and methods of analysis, strategic planning and process management restructuring.

Science is still liable for the lack of a method to study and design of transportation structures covering a systematic basis factors determining the structure. This defines the main objectives of this paper. It is oriented towards the:

- detection of unresolved theoretical and methodological problems in this area; 
- output of the main factors determining the structures and principles for restructuring;

- research and analysis of existing structures;

- output of the main directions for improvement of the structures of transport and developing a methodology for testing and analysis.
The results of the study can be used as an option for evaluating the proposed development of further extensive studies, and their performance and for a particular practical realization of the structural changes.

\section{BIBLIOGRAPHY}

Deming, W. E. (2014). Novata ikonomika za indoostriyata, pravityelstvoto i obrazovaniyeto. Sofia: Rexintegra.

Fathutdinov, R. A. (2001). Organizacija proizvodstva (in Russian ed.). Moskva: INFRA-M.

Heath, C., \& Heath, D. (2010). Switch: How to change things when change is hard. New York: Broadway Books.

Knowles, T. W. (1989). Management science : building and using models. Homewood, III: IRWIN.

Lashr, W., \& Popova, Z. (2001). Stratyeguichyesko mislyenye za dryebniya biznyes i nyeguovitye podrazdyelyeniya (in Bulgarian ed.). Sofia: Lik.

Mirchyev, A. (1996). Proizvodstvyen myenidzmnt: Kak da oopravlyavamye promishlyeno pryedpriyatiye (in Bulgarian ed.). Sofia: Princeps.

Received for publication: $\quad$ 02.02.2014

Revision received: $\quad 02.04 .2014$

Accepted for publication: $\quad 23.06 .2014$

\section{How to cite this article?}

Style - APA Sixth Edition

Vasilev, V. (2014, 07 15). Change management through improvement of the production structure of transport - New challanges. (Z. Čekerevac, Ed.) MEST Journal, 2(2), 258-265. doi:10.12709/mest.02.02.02.26

Style - Chicago Fifteenth Edition:

Vasilev, Vasko. 2014. "Change management through improvement of the production structure of transport - New challanges." Edited by Zoran Čekerevac. MEST Journal (MESTE) 2 (2): 258265. doi:10.12709/mest.02.02.02.26.

Style - GOST Name Sort:

Vasilev Vasko Change management through improvement of the production structure of transport New challanges [Journal] // MEST Journal / ed. Čekerevac Zoran. - Belgrade : MESTE, 07 15, 2014. 2 : Vol. 2. - pp. 258-265.

Style - Harvard Anglia:

Vasilev, V., 2014. Change management through improvement of the production structure of transport New challanges. MEST Journal, 15 07, 2(2), pp. 258-265.

Style - ISO 690 Numerical Reference:

Change management through improvement of the production structure of transport - New challanges. Vasilev, Vasko. [ed.] Zoran Čekerevac. 2, Belgrade : MESTE, 07 15, 2014, MEST Journal, Vol. 2, pp. 258-265. 